\title{
STUDI KARAKTERISTIK KAMPAS REM KENDARAAN PENUMPANG TYPE OES (ORIGINAL EQUIPMENT SPAREPART) DAN AM (AFTER MARKET) PADA DRY DAN WET SLIDING
}

\author{
Rovilla Kennedy ${ }^{1}$, Eko Surojo ${ }^{1}$, Wijang Wisnu Raharjo ${ }^{1}$ \\ ${ }^{1}$ Teknik Mesin - Universitas Sebelas Maret \\ e-mail addres : ugm.kennedy@gmail.com
}

\begin{tabular}{|c|c|}
\hline Keywords: & Abstract : \\
\hline $\begin{array}{l}\text { Friction Coefficient, Brake Pad } \\
\text { Characteristics, The Specific Wear, } \\
\text { dry and wet sliding }\end{array}$ & $\begin{array}{l}\text { Brake pad is one of the components of a motor vehicle which is } \\
\text { served to slow or stop the rate of vehicle. The brake pad of automotive } \\
\text { vehicle on the market is divided into three types that are an OEM (original } \\
\text { equipment manufacturer), OES (original equipment spare parts) and AM } \\
\text { (aftermarket). The brake pad operates under various conditions of dry or } \\
\text { wet sliding. The majority of researchers investigated brake pad } \\
\text { characteristic on dry sliding. Studies of wet braking behavior are rare in } \\
\text { the tribology literature. Therefore, this research performed testing of } \\
\text { friction characteristics of dry and wet sliding by using brake pad type OES } \\
\text { and AM on a passenger vehicle. Each brake pad tested using the machine } \\
\text { pin on disc tribometer type and observed using SEM. The result showed } \\
\text { that the brake pad type OES has a good stability on testing dry sliding and } \\
\text { wet sliding. In addition, passenger type brake pad OES has specific wear } \\
\text { low so more durable in used. Meanwhile the results of SEM showed that } \\
\text { the friction layer were not formed during wet sliding. }\end{array}$ \\
\hline
\end{tabular}

\section{PENDAHULUAN}

Perkembangan industri otomotif di Indonesia memiliki peningkatan yang sangat pesat. Dengan semakin beragamnya tipe, merk, dan jumlah kendaraan bermotor, kebutuhan akan spare parts otomotif juga semakin meningkat. Salah satu komponen yang terdapat dalam kendaraan bermotor adalah kampas rem. Kampas rem merupakan salah satu komponen kendaraan yang berfungsi untuk memperlambat laju kendaraan. Jenis kampas rem yang paling umum digunakan di semua kelas kendaraan modern adalah 'komposit resin-bonded'. Komposit resin-bonded pada umumnya dibagi menjadi 3 kelas, yaitu kampas rem non-asbes organic (NAO), logam rendah (LM), dan kampas rem semi logam (SM) [1].

Penelitian di bidang medis menyatakan bahwa kampas rem dari serat asbestos berbahaya bagi kesehatan yang bisa mengakibatkan kanker paru-paru dan juga gangguan pada saluran pernafasan. Pada tahun 1986, badan perlindungan lingkungan Amerika Serikat atau Environmental Protection Agency mengumumkan bahwa larangan pemakaian serat asbestos pada kampas rem kendaraan bermotor. Atas dikeluarkannya larangan tersebut maka semua industri otomotif yang berhubungan dengan pembuatan kampas rem pada kendaraan bermotor mengharuskan semua kendaraan keluaran baru agar menggunakan kampas rem non-asbes mulai September 1993. Pada tahun 1996 badan perlindungan lingkungan amerika serikat juga mengeluarkan kebijakan yang berlaku pada produsen kampas rem yang aftermarket untuk memproduksi kampas rem non-asbes [2].

Secara umum terdapat dua type kampas rem yang beredar di pasaran yaitu OES (original equipment sparepart) dan AM (after market). Kampas rem type OES adalah kampas rem yang disediakan oleh pabrikan kendaraan. Jenis kampas rem ini adalah jenis kampas rem yang biasanya direkomendasikan oleh pabrikan kendaraan kepada konsumen untuk mengganti kampas rem yang sudah habis. Sedangkan kampas rem type AM merupakan kampas rem yang bukan rekomendasi dari perusahaan kendaraan bermotor. Harga kampas rem AM bisa lebih murah dari kampas rem OES tetapi juga bisa lebih mahal dari kampas rem type OES. Namun pada type kampas rem AM yang dipakai dalam penelitian ini menggunakan type kampas rem dengan harga yang lebih murah dari kampas rem OES. Banyaknya variasi harga pada kampas rem dikarenakan adanya perbedaan komposisi bahan pembuat pada kampas rem, sehingga akan mempengaruhi karakteristik dari semua jenis kampas rem. Namun pada dasarnya dipengaruhi oleh kondisi tekanan kontak dan kecepatan pada saat pengereman. 
Di dalam pemakaiannya, kampas rem beroperasi di bawah berbagai kondisi, baik itu pada kondisi kering maupun pada kondisi basah/hujan. Sebagian besar peneliti melakukan pengujian kampas rem pada gesekan kering. Publikasi mengenai dampak air yang berada dalam pengereman pada gesekan basah sangat jarang dilakukan pengujian. Terkait dengan penjelasan diatas maka pada penelitian ini akan dilakukan pengujian karakteristik pada gesekan kering dan gesekan basah dengan menggunakan kampas rem type OES dan AM pada kendaraan penumpang. Sebuah alat tribometer dengan type pin-on-disk dapat digunakan untuk menguji koefisien gesek dan keausan spesifik kampas rem pada kondisi temperatur ruangan [3]. Sementara itu, struktur mikro dan komposisi kimia pada permukaan kontak kampas rem setelah pengujian tribology type pin-on-disk dapat dilakukan dengan pengujian mikroskop elektron atau SEM [4].

Karakteristik kampas rem dapat diketahui dengan menggunakan pengujian tribology. Pada dasarnya karakteristik kampas rem dipengaruhi oleh kondisi tekanan kontak dan kecepatan sliding pada saat pengereman. Peningkatan kecepatan sliding dan tekanan kontak ataupun sebaliknya akan sangat mempengaruhi koefisien gesek yang dihasilkan [5]. Dengan dinaikkannya tekanan kontak pengereman, nilai koefisien gesek kampas rem yang bagus sebaiknya memiliki nilai koefisien gesek yang stabil. Dalam pengujian juga bisa dilakukan dengan pembebanan tekanan kontak konstan atau kecepatan konstan. Pengujian dry sliding dan wet sliding dilakukan untuk mengetahui perbandingan koefisien gesek yang lebih maksimal pada kampas rem. Perubahan nilai dari koefisien gesek tergantung pada bahan dan kondisi pengereman. Hasil pengujian koefisien gesek dijadikan acuan untuk mengetahui masa penggunaan atau keawetan dari kampas rem yang diuji [6] [7].

Dalam dua dekade terakhir penggunaan asbes sangat poluler untuk bahan pembuatan kampas rem dimana memiliki kekuatan yang baik dan memiliki ketahanan terhadap panas yang baik. Namun hasil penelitian medis menunjukkan bahwa asbes sangat berbahaya bagi kesehatan. Larangan penggunaan bahan asbes mengharuskan pada kendaraan baru untuk menggunakan kampas rem berbahan non-asbestos, tapi beberapa produsen kendaraan masih tetap menggunakan material asbestos. Hal tersebut dikarenakan material asbestos memiliki daya tahan terhadap panas yang stabil mencapai $650^{\circ} \mathrm{C}$, konduktifitas termal yang rendah, kuat, lentur dan beberapa karakteristik yang siknifikan [5][8].

\section{METODOLOGI PENELITIAN \\ Bahan}

Bahan yang digunakan dalam penelitian ini adalah kampas rem kendaraan penumpang type original equipment sparepart (OES) dan aftermarket (AM) yang dari harga lebih murah daripada type OES.

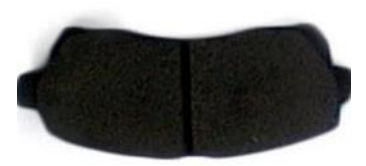

(a) OES

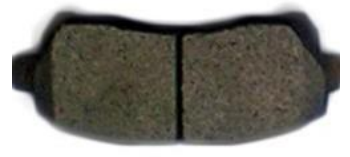

(b) AM
Gambar 1. Kampas rem kendaraan penumpang

\section{Proses Persiapan}

Proses persiapan spesimen dilakukan untuk mendapatkan ukuran spesimen agar sesuai dengan tahap pengujian. Kampas rem dipotong dengan dimensi panjang $10 \mathrm{~mm}$, lebar $10 \mathrm{~mm}$ dan tebal \pm 15 $\mathrm{mm}$.

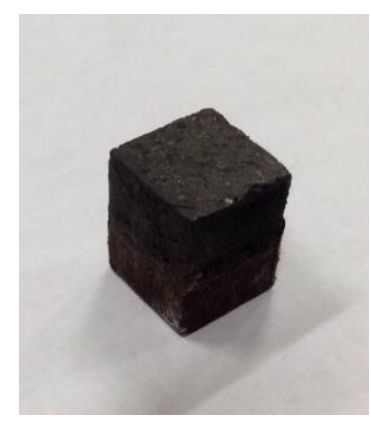

(a) OES

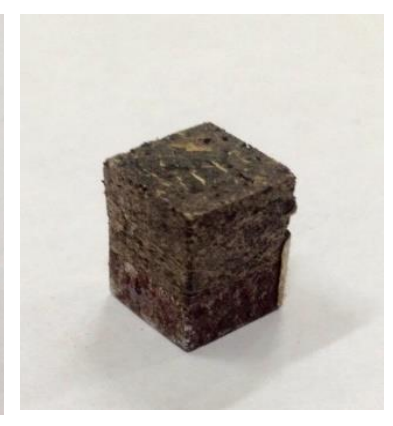

(b) AM
Gambar 2. Spesimen uji

\section{Pengujian}

Pengujian spesimen kampas rem yang dilakukan adalah sebagai berikut:

a. Uji koefisien gesek

Pada pengujian koefisien gesek dilakukan dua pengujian antara lain pengujian dengan dry sliding dan wet sliding. Pada gesekan basah laju aliran air yang digunakan sebesar $10 \mathrm{ml} / \mathrm{menit}$. Semua pengujian dilakukan dalam suhu ruangan $\left(20-25^{\circ} \mathrm{C}\right)$. Spesimen yang digunakan pada pengujian koefisien gesek adalah spesimen berdimensi panjang dan lebar $10 \mathrm{~mm}$ dan tebal $\pm 15 \mathrm{~mm}$. 
\begin{tabular}{l|l} 
Mekanika: Majalah Ilmiah Mekanika & 30 \\
Volume 18 Nomor 1 Maret 2019 &
\end{tabular}

digunakan untuk mengetahui komposisi dan informasi kristalografi pada spesimen kampas rem

\section{HASIL DAN PEMBAHASAN}

Hasil pengujian koefisien gesek kampas rem OES dan AM pada dry dan wet sliding terhadap variasi tekanan kontak

Hasil data koefisien gesek yang dihasilkan dari pengujian koefisien gesek pada saat dry sliding dan wet sliding menunjukkan bahwa pada wet sliding memiliki nilai koefisien gesek lebih rendah dibandingkan dengan dry sliding. Pada variasi tekanan kontak menunjukkan kampas rem memiliki kecenderungan menurun pada saat dry sliding. Hal tersebut disebabkan oleh terbentuknya fase oksida dengan semakin tinggi suhu yang diberikan yang dipengaruhi oleh penambahan tekanan. Oksida memiliki karakteristik pelumas sehingga menurunkan nilai koefisien gesek [9].

Penambahan tekanan kontak menyebabkan melemahnya ikatan tersebut sehingga menyebabkan turunnya nilai koefisien gesek [10]. Perubahan nilai koefisien gesek pada kampas rem type OES lebih rendah dibandingkan dengan kampas rem type AM. Perbedaan komposisi dan bahan pembuatan kampas rem sangat mempengaruhi nilai koefisien gesek pada kampas rem. Pengujian pada variasi tekanan kontak dry sliding kampas rem type OES nilai koefisien gesek masuk standard pembuatan kampas rem pada perusahaan kampas rem dengan kisaran $0.3-0.45$.

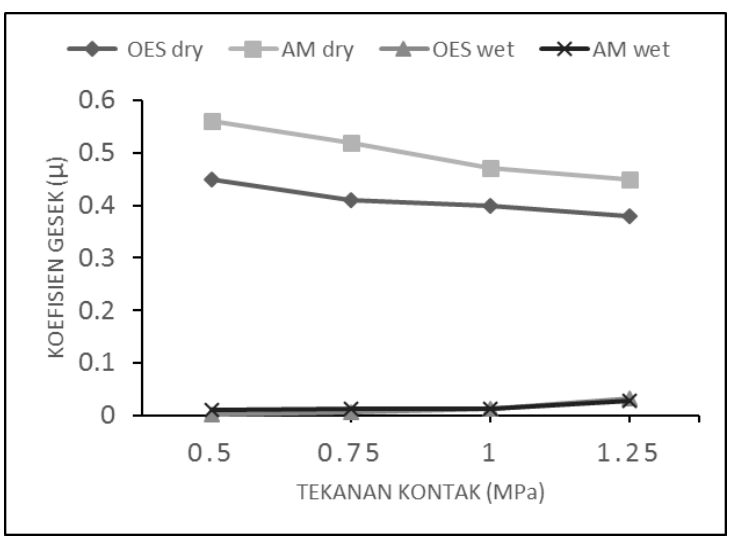

Gambar 5. Hasil pengujian koefisien gesek kampas rem OES dan AM pada dry dan wet sliding terhadap variasi tekanan kontak

Sementara itu, kampas rem pada saat wet sliding dengan variasi tekanan kontak menunjukkan trend naik. Hal ini disebabkan karena semakin dinaikkan tekanan kontak maka lapisan air yang masuk pada gesekan kampas rem dengan piringan menjadi semakin berkurang sehingga menjadikan nilai koefisien gesek kedua type kampas rem OES dan AM menjadi naik [11]. Hasil dari pengujian koefisien 


\section{Mekanika: Majalah Ilmiah Mekanika 31 Volume 18 Nomor 1 Maret 2019}

kampas rem type OES sangat kecil karena temperatur yang rendah menjadikan ikatan partikel penyusun dalam kampas rem tetap kuat sehingga sulit untuk bertambah panjang. Adanya $\mathrm{Cu}$ pada kampas rem dapat ditunjukkan dari foto SEM-EDS pada Gambar 7.

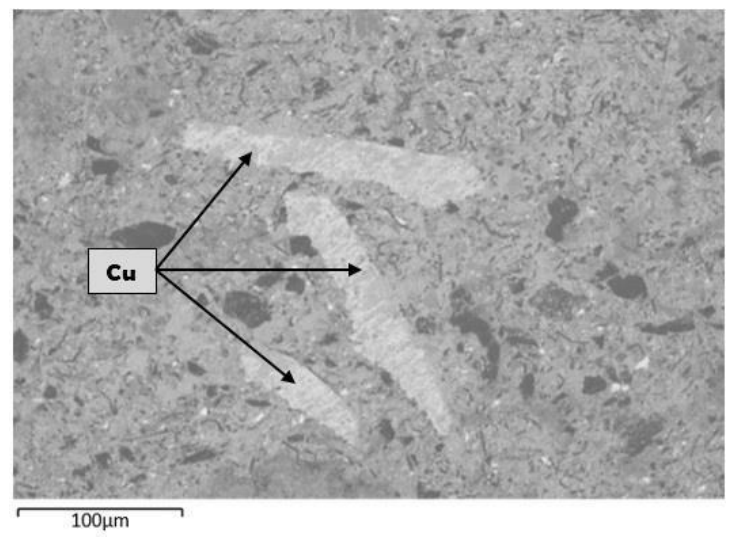

Gambar 7. foto SEM-EDS kampas rem kendaraan penumpag type OES

Tabel 1: Data hasil EDS di bagian permukaan kontak kampas rem type OES

\begin{tabular}{|l|l|c|}
\hline No & \multicolumn{1}{|c|}{ Elemen } & Prosentase (\%) \\
\hline 1 & Copper $(\mathrm{Cu})$ & 38.8 \\
\hline 2 & Oxygen $(\mathrm{O})$ & 20.5 \\
\hline 3 & Iron $(\mathrm{Fe})$ & 8.2 \\
\hline 4 & Calcium $(\mathrm{C})$ & 7.9 \\
\hline 5 & Titanium $(\mathrm{Ti})$ & 3.8 \\
\hline 6 & Barium $(\mathrm{Ba})$ & 2.8 \\
\hline 7 & Chromium $(\mathrm{Cr})$ & 1.9 \\
\hline 8 & Silicon $(\mathrm{Si})$ & 1.6 \\
\hline 9 & Calcium $(\mathrm{Ca})$ & 1.4 \\
\hline 10 & Sulfur $(\mathrm{S})$ & 1.1 \\
\hline 11 & Magnesium $(\mathrm{Mg})$ & 0.8 \\
\hline 12 & Potassium $(\mathrm{K})$ & 0.8 \\
\hline 13 & Aluminium $(\mathrm{Al})$ & 0.7 \\
\hline
\end{tabular}

Sementara hasil SEM-EDS pada kampas rem kendaraan penumpang type AM tidak ditemukan unsur Copper $(\mathrm{Cu})$ sehingga pada kampas rem kendaraan penumpang type AM menghasilkan kestabilan yang kurang baik. Selain berpengaruh pada kestabilan pada kampas rem, komposisi bahan pembuatan kampas rem juga sangat mempengaruhi kinerja dan keawetan kampas rem. Pengambilan foto SEM-EDS pada kampas rem type AM sama seperti pada kampas rem kendaraan penumpang type OES yaitu pada bagian permukaan kampas rem. Hasil foto SEM-EDS pada kampas rem kendaraan penumpang type AM dapat ditunjukkan pada Gambar 8 dan Tabel 
2 menunjukkan komposisi kimia permukaan kampas rem type AM.

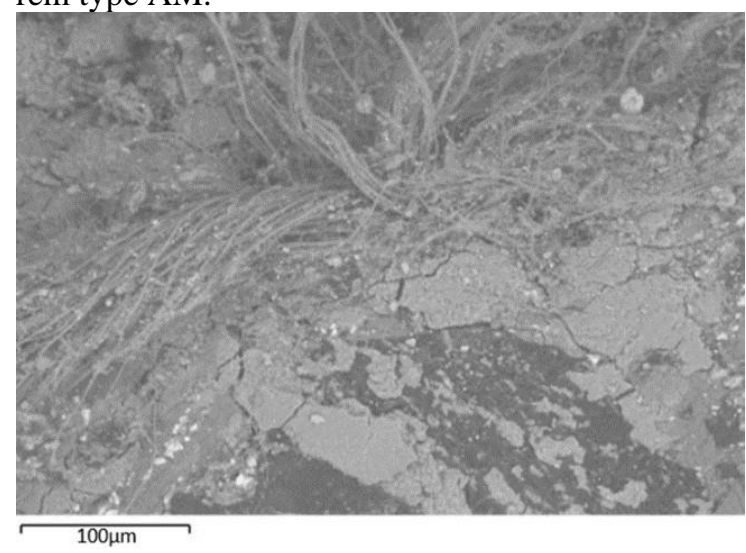

Gambar 8. foto SEM-EDS kampas rem kendaraan penumpag type AM

Tabel 2: Data hasil EDS di bagian permukaan kontak kampas rem type AM

\begin{tabular}{|l|l|c|}
\hline No & \multicolumn{1}{|c|}{ Elemen } & Prosentase $(\%)$ \\
\hline 1 & Oxygen $(\mathrm{O})$ & 38.7 \\
\hline 2 & Carbon $(\mathrm{C})$ & 18.3 \\
\hline 3 & Magnesium $(\mathrm{Mg})$ & 12.5 \\
\hline 4 & Iron $(\mathrm{Fe})$ & 12.1 \\
\hline 5 & Silicon $(\mathrm{Si})$ & 8.9 \\
\hline 6 & Barium $(\mathrm{Ba})$ & 3.4 \\
\hline 7 & Calcium $(\mathrm{Ca})$ & 2.3 \\
\hline 8 & Chromium $(\mathrm{Cr})$ & 1.0 \\
\hline 9 & Sulfur $(\mathrm{S})$ & 0.9 \\
\hline 10 & Natrium $(\mathrm{Na})$ & 0.5 \\
\hline 11 & Potassium $(\mathrm{K})$ & 0.5 \\
\hline 12 & Titanium $(\mathrm{Ti})$ & 0.4 \\
\hline 13 & Aluminium $(\mathrm{Al})$ & 0.3 \\
\hline 14 & Chlorine $(\mathrm{Cl})$ & 0.2 \\
\hline
\end{tabular}

Pada kampas rem type AM ditemukan unsur $\mathrm{Mg}$ dan Si yang cukup tinggi yaitu Magnesium $(\mathrm{Mg})$ sebesar $12.5 \%$ dan Silicon (Si) sebesar $8.9 \%$. Hal ini membuktikan bahwa pada kampas rem type AM memang benar-benar mengandung material asbestos. Hal ini juga sependapat dengan Blau bahwa material asbestos memiliki rumus kimia $\mathrm{Mg}_{3} \mathrm{Si}_{2} \mathrm{O}_{5}(\mathrm{OH})_{4}$ [2]. Sementara itu, pada kampas rem saat wet sliding menunjukkan kecenderungan lebih rendah pada variasi kecepatan sliding. Hal ini disebabkan karena adanya efek hidrodinamik yang mendominasi pada saat dinaikkannya kecepatan sliding [9]. Ketika air diterapkan dalam pengujian, gesekan antarmuka kampas rem dan piringan hampir tidak ada kontak langsung seperti pada halnya bantalan luncur. Wet sliding tidak hanya lapisan air yang dihasilkan tetapi juga kontak antar permukaan pada kampas rem dan piringan akan berkurang dan juga panas tinggi yang dihasilkan gesekan akan didinginkan pada saat wet sliding. Selain itu ketika air diterapkan dalam pengujian juga akan menjadikan kerusakan permukaan pada kampas rem.

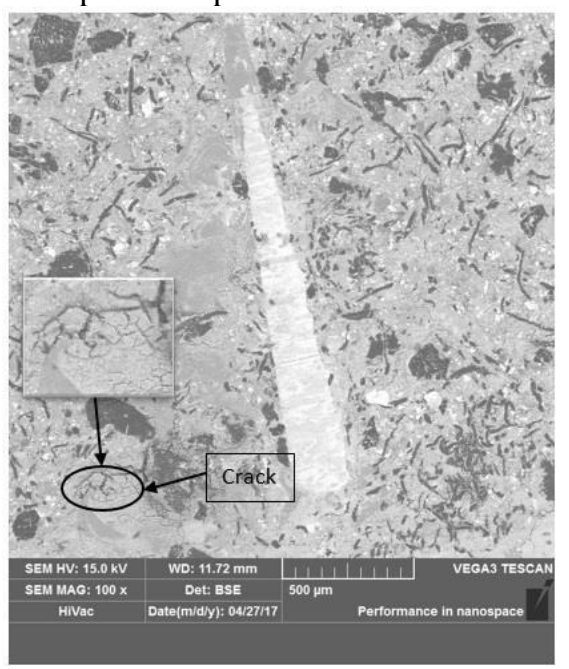

Gambar 9. Hasil retakan dari foto SEM kampas rem OES wet sliding

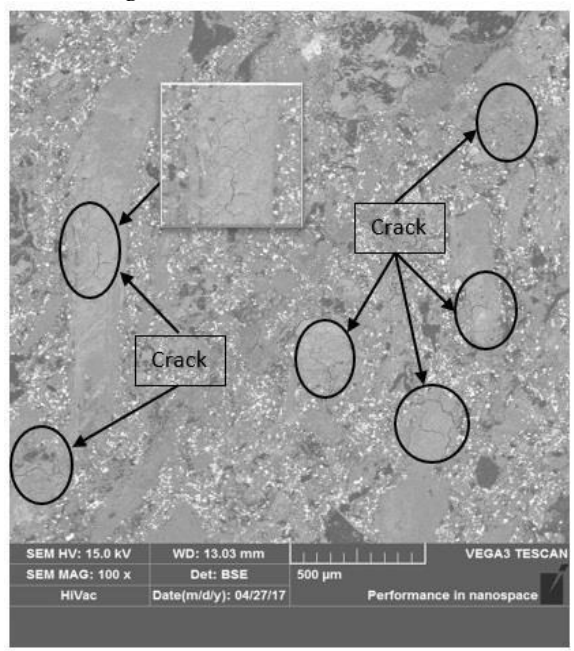

Gambar 10. Hasil retakan dari foto SEM kampas rem AM wet sliding

Hasil foto SEM setelah dilakukan pengujian wet sliding kampas rem tampak kerusakan pada permukaan kampas rem kendaraan penumpang type OES dan AM. Pada kampas rem type OES menunjukkan kerusakan yang sedikit pada permukaannya. Sementara itu pada kampas rem type AM menunjukkan banyaknya kerusakan pada permukaan kampas rem. Kerusakan permukaan hampir merata pada bagian permukaan kampas rem type AM. Hal ini disebabkan karena air yang terus membasahi permukaan kampas rem sehingga air meresap pada permukaan seiring bertambahnya kecepatan sliding atau tekanan kontak. Selain itu 
komposisi bahan untuk membuat kampas rem juga sangat berpengaruh pada kekuatan kampas rem. Terbukti bahwa pada kampas rem type OES hanya sedikit kerusakan yang terjadi. Selain kerusakan permukaan pada saat wet sliding, efek yang ditimbulkan dari adanya air pada saat pengujian menjadikan partikel kampas rem yang terbentuk dari gesekan antarmuka pada saat pengujian dry sliding tidak terbentuk pada saat pengujian wet sliding sehingga partikel gesek sulit terbentuk pada saat wet sliding, bukti ini juga diperkuat oleh Blau dan McLaughlin 2003, El-Tayeb dan Liew 2007, Eriksson 2001 menyatakan bahwa air dapat menyulitkan pembentukan partikel yang diakibatkan dari gesekan sehingga dapat mempengaruhi pengereman dan menurunkan nilai koefisien gesek jauh dari standard yang ada kisaran 0.3-0.45.

Keberadaan air yang mengalir pada piringan secara kontinyu menjadikan piringan tetap pada keadaan dingin sehingga memiliki dampak yang signifikan terhadap kecepatan gesekan, keberadaan lapisan air mengurangi ke tingkat yang tidak dapat diterima untuk sistem pengereman [11]. Hasil dari pengujian koefisien gesek pada pengaruh kecepatan sliding terhadap koefisien gesek pada wet sliding diperoleh nilai koefisien gesek berada pada kisaran Mixed lubrication dengan nilai koefisien gesek kisaran (0.003 - 0.1) seiring dinaikkannya kecepatan sliding sehingga hal ini dianggap serius dan berbahaya bagi pengendara pada saat kondisi basah/hujan.

\section{Hasil Pengujian Keausan Spesifik}

Hasil data pengujian keausan spesifik diperlihatkan pada Gambar 7. Nilai keausan spesifik pada kampas rem kendaraan penumpang type OES adalah sebesar $1,9 \times 10^{-8} \mathrm{~mm}^{2} / \mathrm{N}$. Sedangkan pada kampas rem kendaraan penumpang type AM adalah sebesar $2,5 \times 10^{-8} \mathrm{~mm}^{2} / \mathrm{N}$. Kampas rem kendaraan penumpang type OES memiliki nilai keausan spesifik yang lebih rendah dibandingkan dengan kampas rem type AM. Hal ini menunjukkan bahwa kampas rem dengan nilai keausan spesifik yang rendah akan menghasilkan sedikit volume yang hilang sehingga menunjukkan bahwa kampas rem lebih tahan lama dalam penggunaannya [12]. Gambar 4.10 dapat dilihat bahwa nilai keausan spesifik pada kampas rem type OES lebih rendah dibandingkan pada kampas rem type AM. Hal tersebut diduga karena adanya perbedaan acuan dari komposisi bahan yang digunakan dalam pembuatan kampas rem. Perbedaan komposisi bahan tersebut akan berpengaruh pada kualitas dan keawetan pemakaian kampas rem.

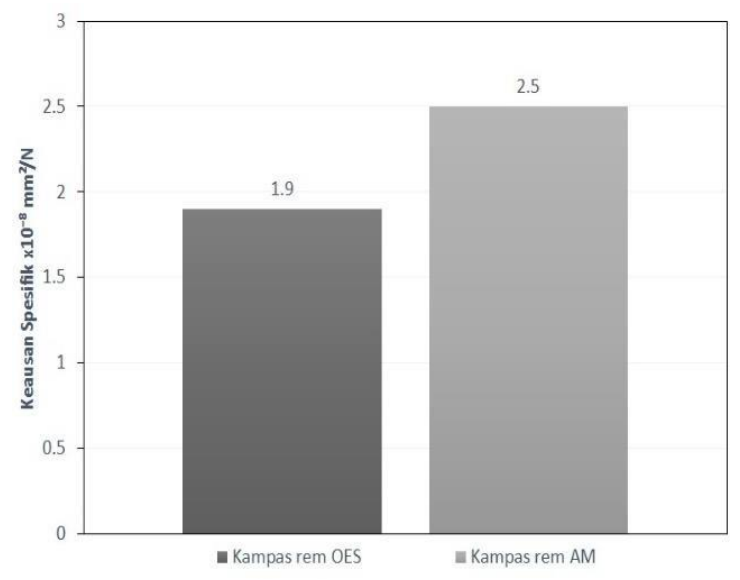

Gambar 11. Hasil pengujian keausan kampas rem type OES dan AM

\section{KESIMPULAN}

Beberapa kesimpulan yang dapat diperoleh dari penelitian yang telah dilakukan adalah sebagai berikut:

1. a. Pengujian dengan variasi tekanan kontak dan kecepatan sliding terhadap koefisien gesek menunjukkan bahwa kampas rem type OES memiliki kestabilan yang baik. Hal ini disebabkan karena kampas rem type OES terdapat kandungan filler logam $\mathrm{Cu}$ yang berfungsi untuk menstabilkan koefisien gesek..

b. Pengujian dengan variasi tekanan kontak dan kecepatan sliding terhadap koefisien gesek wet sliding menunjukkan bahwa nilai koefisien gesek wet sliding lebih rendah dibandingan dengan dry sliding. Hal ini disebabkan karena ketika wet sliding diterapkan dalam pengujian akan menghasilkan lapisan air sehingga gesekan antar permukaan kampas rem dan piringan akan berkurang. Selain itu pada saat pengujian wet sliding tidak terjadi kenaikkan temperatur dikarenakan air yang berada saat pengujian akan mendinginkan permukaan kampas rem dan piringan.

2. Nilai keausan spesifik pada kampas rem kendaraan penumpang type OES memiliki nilai keausan spesifik yang lebih rendah dibandingkan dengan kampas rem type AM. Kampas rem dengan nilai keausan spesifik yang rendah akan menghasilkan sedikit volume yang hilang sehingga menunjukkan bahwa kampas rem lebih tahan lama dalam penggunaannya. Perbedaan komposisi bahan tersebut akan berpengaruh pada kualitas dan keawetan pemakaian kampas rem. 


\section{DAFTAR PUSTAKA}

[1] A. Day, "Chapter 2 - Friction and Friction Materials BT - Braking of Road Vehicles," pp. 9-34, 2014

[2] P.J. Blau, "Compositions , Functions , and Testing of Friction Brake Materials and Their Additives," Energy. Vol. 27, no. 38, 2001.

[3] U.D. Idris, V.S. Aigbodion, I.J. Abubakar, and C.I. Nwoye, "Eco-friendly asbestos free brake-pad: Using banana peels," J. King Saud Univ. - Eng. Sci. vol. 27, pp. 185-192, 2015

[4] R. Yun, P. Filip, and Y. Lu, "Performance and evaluation of eco-friendly brake friction materials," Tribol. Int. vol. 43, pp. 2010-2019, 2010.

[5] K.W. Liew and U. Nirmal, "Frictional performance evaluation of newly designed brake pad materials," Mater. Des.vol. 48, pp. 25-33,2013.

[6] N.S.M. EL-Tayeb and K.W. Liew, "On the dry and wet sliding performance of potentially new frictional brake pad materials for automotive industry," Wear. vol. 266, pp. 275-287, 2009.

[7] G. Straffelini, P.C. Verma, I. Metinoz, R. Ciudin, G. Perricone, and S. Gialanella, "Wear behavior of a low metallic friction material dry sliding against a cast iron disc: Role of the heattreatment of the disc," Wear. vol. 348-349, pp. 10-16, 2016.

[8] J.R. Laguna-Camacho, G. Juárez-Morales, C. Calderón-Ramón, V. Velázquez-Martínez, I. Hernández-Romero, J. V. Méndez-Méndez, and M. Vite-Torres, "A study of the wear mechanisms of disk and shoe brake pads," Eng. Fail. Anal. vol. 56, pp. 348-359, 2015.

[9] P.J. Blau and J.C. McLaughlin, "Effects of water films and sliding speed on the frictional behavior of truck disc brake materials," Tribol. Int., vol. 36, pp. 709-715, 2003.

[10] M. Kumar and J. Bijwe, "Role of different metallic fillers in non-asbestos organic (NAO) friction composites for controlling sensitivity of coefficient of friction to load and speed," Tribol. Int. vol. 43 pp. 965-974, 2010.

[11] K.W. Liew, "Effect of water spray on friction and wear behaviour of noncommercial and commercial brake pad materials," vol. 8, pp. 135- 144, 2008.

[12] N. Aranganathan, V. Mahale, J. Bijwe, "Author' s Accepted Manuscript," Wear. 2016. 